\title{
Assessment of Competencies of Medical Students in Conducting 'Normal Delivery' using Various Tools
}

\author{
${ }^{1}$ Ashok Verma, ${ }^{2}$ Amrita Singhal, ${ }^{3}$ Suresh Verma, ${ }^{4}$ Shivani Vashist
}

\begin{abstract}
Introduction: It is well established that the graduating medical practitioner must have knowledge and expertise in women's health. A list of competencies has been developed for specialist training, and however, expected competencies have not been defined for undergraduate medical students in India.
\end{abstract}

Aims and objectives: To assess the competencies of the students in conducting normal delivery and common clinical tasks using various tools.

Methods: Forty-four final year medical students and 26 teachers participated in the study that was conducted over 4 months. Planned curriculum, teaching methods, and assessment plans were displayed prominently. Faculties and students were sensitized regarding assessment using multiple choice questions (MCQS), short answer questions (SAQS), objective structured clinical examination (OSCE), and direct observation of procedural skills (DOPS). Self-assessment by the students was also done in each competency.

Results: All the faculties liked the teaching-learning-assessment method $>3$ on the Likert scale. Each student assisted in conducting 20-40 deliveries. Mean score in MCQ and SAQ was $63.6 \%, 71.7 \%$ in OSCE, and $70.7 \%$ in DOPS. Mean score in assisting normal delivery by all methods was $77 \%$. Lower than expected score was observed in partogram interpretation $(61.3 \%)$, and postpartum care (55\%). Student self-assessment is lower than faculty expectations in postpartum care $(34.3 \%)$, family planning services $(50.3 \%)$, and newborn resuscitation and care $(58.7 \%)$.

Conclusion: Students are confident in assisting normal delivery. They are less confident in partogram interpretation, neonatal resuscitation and care, postpartum care, and family planning service. Assessment using various tools and student self-assessment is important in the identification of thrust areas in curriculum planning.

Keywords: Assessment, Competencies, Direct observation of procedural skills, Medical students, Normal delivery, Objective structured clinical examination.

\footnotetext{
${ }^{1}$ Associate Professor, ${ }^{2,4}$ Junior Resident, ${ }^{3}$ Professor

1-4Department of Obstetrics and Gynaecology, Dr Rajendra Prasad Government Medical College, Kangra, Himachal Pradesh, India

Corresponding Author: Ashok Verma, Associate Professor, Department of Obstetrics and Gynaecology, Dr Rajendra Prasad Government Medical College, Kangra, Himachal Pradesh, India, e-mail: dr.ashok_verma@yahoo.com
}

How to cite this article: Verma A, Singhal A, Verma S, Vashist S. Assessment of Competencies of Medical Students in Conducting 'Normal Delivery' using Various Tools. World $\mathrm{J}$ Anemia 2018;2(2):47-50.

\section{Source of support: Nil \\ Conflict of interest: None}

\section{INTRODUCTION}

Since the 1950s, there has been a rapid and extensive change in the way assessment is conducted in medical education. Several new methods of assessment have been developed and implemented over this time, and they have focused on clinical skills, communication skills, procedural skills and, professionalism. ${ }^{1}$ Clinical teachers have an important role to play in comprehensive assessment plan as the students spend an increasing amount of their time in clinical settings, and should be assessed there.

It is well established that the graduating medical practitioner must have knowledge and expertise in women's health. While competency maps have been developed for specialist training, expected competencies have not been defined for medical students. Efforts have been made in the United States to identify priority learning objectives in obstetrics and gynecology. In India, there have been no studies identifying core competencies in obstetrics and common clinical tasks that are required in practice. Workplace-based assessment is strongly recommended for inclusion in the in-training assessment program for any competency-based training. ${ }^{3}$

\section{AIMS AND OBJECTIVES}

To assess the competencies of the students in conducting normal delivery and common clinical tasks using various tools.

Self-evaluation by the medical students of their confidence in common clinical tasks in obstetrics.

\section{METHODS}

The study was conducted after approval of the ethics committee of the institution was obtained. Forty four final year Bachelor of Medicine, Bachelor of Surgery (MBBS) students and 26 teachers participated in the study that was conducted over four month's period from 1st May 
to 31st August 2015 at Dr Rajendra Prasad Government Medical College, Kangra at Tanda, Himachal Pradesh, India. Curriculum planned, teaching roster, and assessment plans were prominently displayed on the notice board after sensitization of the students and the teachers. The assessment was carried out by various faculties by MCQS, SAQS, Viva, Logbooks, OSCE, and DOPS at the end of 1-month training. Before OSCE and DOPS, students and teachers were explained and sensitized as to what they were supposed to do on these stations.

Teaching-learning-assessment plan was prepared and is shown in Table 1. Faculty expectations of the confidence of the students at the end of posting are shown in Table 2.

\section{RESULTS}

Each student conducted a minimum of 20 deliveries under the supervision and independently as shown in Table 3.

In each competency mean score obtained by the students in MCQS/SAQS testing knowledge domain, student, and the faculty expectations is shown in Table 4.

Table 5 shows the mean score obtained by the students in DOPS and OSCE and compared with the selfassessment and the faculty expectations.
Graph 1 is the Bar diagram showing a comparison of faculty expectations, student self-assessment, MCQS/ SAQS scores, scores on OSCE and DOPS.

\section{DISCUSSION}

Majority of the participants (75.1\%) in the study reported good perceived overall confidence to recognize and manage normal delivery and common obstetric problems faced in an emergency in the labor room. Partograph interpretation is an important core competency in which students performed less (61.3\%) than faculty expectations (70\%). They were significantly less confident with postpartum care (55\%) another core competency. These areas can be considered subsequently during the internship. Students who assisted a greater number of births had higher scores in these competencies. Similar observations were made by Yigzaw et al. ${ }^{4}$ who observed better performance by the students who assisted more number of births. Providing additional 'skills and drills' practical training has proved to be effective in increasing the knowledge and skills of healthcare providers. ${ }^{5}$ (Bettina UTZ)

Interestingly student self-assessment showed lower confidence in postpartum care $(34.5 \%)$, family planning

Table 1: Teaching-learning-assessment plan

\begin{tabular}{ll}
\hline Departmental curriculum committee meeting & \begin{tabular}{l} 
Identified core competencies to be mastered by the students at the end of 1-month \\
\hline Teaching-learning method used
\end{tabular} \\
$\begin{array}{ll}\text { Demonstrations and hands on training daily by Junior residents, senior residents } \\
\text { and consultants in obstetrics skills }\end{array}$ \\
\hline Various assessment method by six teachers & MCQs, SQQ-structured questions covering each competency with equal marks \\
& Logbook review \\
& DOPS-6 encounters \\
& OSCE-10 stations on day 25-day 30 \\
\hline Student feedback at the end of posting & Self assessment in the core competencies \\
\hline Assessment criteria & Each student assisted minimum 20 deliveries and entered in log book duly verified \\
& by Senior residents \\
& Students-Mean performance in OSCE and DOPS of $>60 \%$ in each competency \\
& Faculty-All the teachers like the programme $>3$ on Likert scale \\
& Students-Mean performance in OSCE and DOPS of $>60 \%$ in each competency \\
& Faculty-All the teachers like the programme $>3$ on Likert scale \\
\hline
\end{tabular}

Table 2: Faculty expectations of the confidence of the students at the end of posting

Expected to function independently without direct Expected to be able to undertake supervision task under direct supervision

- Antenatal history taking

- Assisting normal delivery

- Partograph interpretation

- Active management of 3rd stage of labour

- New born resuscitation

task under direct supervision

- Parentral administration of antibiotics and oxytocin

- Administration of anticonvulsants

- Assessment and decision

making in hemorrhage

- Assessment diagnosis and

decision making in eclampsia

- Preterm labour management

- Episiotomy

- Postpartum care
Expected to describe the task only

- Exploration of cervical and vaginal tear

- Vacuum assisted delivery

- Family planning services 
Table 3: Number of deliveries conducted by the students in 1 month

\begin{tabular}{ll}
\hline Number of deliveries assisted/conducted by the students & Mean $=26.1524 .5$ \\
\hline & $\mathrm{SD}=5.37$ \\
& Median $=24.5$ \\
Cases entered in log book, verified by the Senior residents & Minimum $=20$ \\
\hline
\end{tabular}

Table 4: Competencies: Self assessment, faculty expectations and MCQ/SAQ scores

\begin{tabular}{llll}
\hline & & & Mean MCQs, SAQ \\
Scompetency & Self assessment & Faculty expectation & 75 \\
\hline Antenatal history taking & 72.3 & 100 & 65 \\
Assisting normal delivery & 89 & 70 & 70 \\
Partograph interpretation & 85.6 & 70 & 65 \\
Active management of 3rd stage & 72.3 & 70 & 64 \\
Newborn resuscitation and care & 58.7 & 70 & 65 \\
Parentral administration of oxytocin and antibiotics & 85.6 & 60 & 60 \\
Anticonvulsant administration & 88.4 & 60 & 63 \\
Assessment in hemorrhage & 88.4 & 60 & 65 \\
Assessment in eclampsia & 88.4 & 60 & 62 \\
Preterm labour management & 74 & 60 & 63 \\
Episiotomy & 88 & 60 & 63 \\
Postpartum care & 34.3 & 50 & 50 \\
Cervical tear exploration & 76 & 50 & 6 \\
Family planning services & 50.3 & 50 & \\
\hline
\end{tabular}

Mean faculty expectations $=63.6, \mathrm{SD}=12.779(\min =50, \max =100)$

Mean student self assessment $=75.1, \mathrm{SD}=16.37(\min =34.3, \max =89)$

$\mathrm{MCQ}$ and $\mathrm{SAQ}$ scores mean $=65.2, \mathrm{SD}=4.1(\mathrm{~min}=60, \mathrm{max}=75)$

Paired sample t-test done for faculty expectations and mean MCQs/SAQ scores, $t=-0.205$, Sig $=0.842$

Table 5: Mean performance score at each OSCE station and DOPS, and the faculty expectations

\begin{tabular}{|c|c|c|c|}
\hline Competency & $\begin{array}{l}\text { Mean OSCE performance } \\
\text { score at each station }\end{array}$ & $\begin{array}{l}\text { Mean performance } \\
\text { on DOPS }\end{array}$ & $\begin{array}{l}\text { Faculty } \\
\text { expectation }\end{array}$ \\
\hline Antenatal history taking & 72.3 & 65.5 & 100 \\
\hline Assisting normal delivery & 66.1 & 76.8 & 70 \\
\hline Partograph interpretation & 55.5 & 55.5 & 70 \\
\hline Active management of 3 rd stage & 69.1 & 65.3 & 70 \\
\hline Newborn resuscitation & 85.6 & 85.5 & 70 \\
\hline Parentral administration of oxytocin and antibiotics & 85.6 & 85.5 & 60 \\
\hline Anticonvulsant administration & 88.4 & 88.4 & 60 \\
\hline Assessment in hemorrhage & 88.4 & 65 & 60 \\
\hline Assessment in eclampsia & 88.4 & 85 & 60 \\
\hline Preterm labour management & 63.4 & 56 & 60 \\
\hline Episiotomy & 88 & 85.6 & 60 \\
\hline Postpartum care & 46.8 & 56.4 & 50 \\
\hline Cervical tear exploration & 56.4 & 56.3 & 50 \\
\hline Family planning services & 50.3 & 63.6 & 50 \\
\hline
\end{tabular}

\footnotetext{
Mean faculty expectations $=63.6, \mathrm{SD}=12.779(\min =50, \max =100)$

Mean score OSCE $=71.8, \mathrm{SD}=15.6($ minimum $=47$, maximum $=88)$

Mean score DOPS $=70.7, \mathrm{SD}=13.1(\mathrm{~min}=55.5, \max =88.4)$

Paired sample t-test done for faculty expectations and mean OSCE scores,

$\mathrm{t}=-1.694, \mathrm{Sig}=0.114$

Paired sample t-test done for faculty expectations and mean DOPS scores,

$\mathrm{t}=-1.523$, Sig $=0.152$
} 


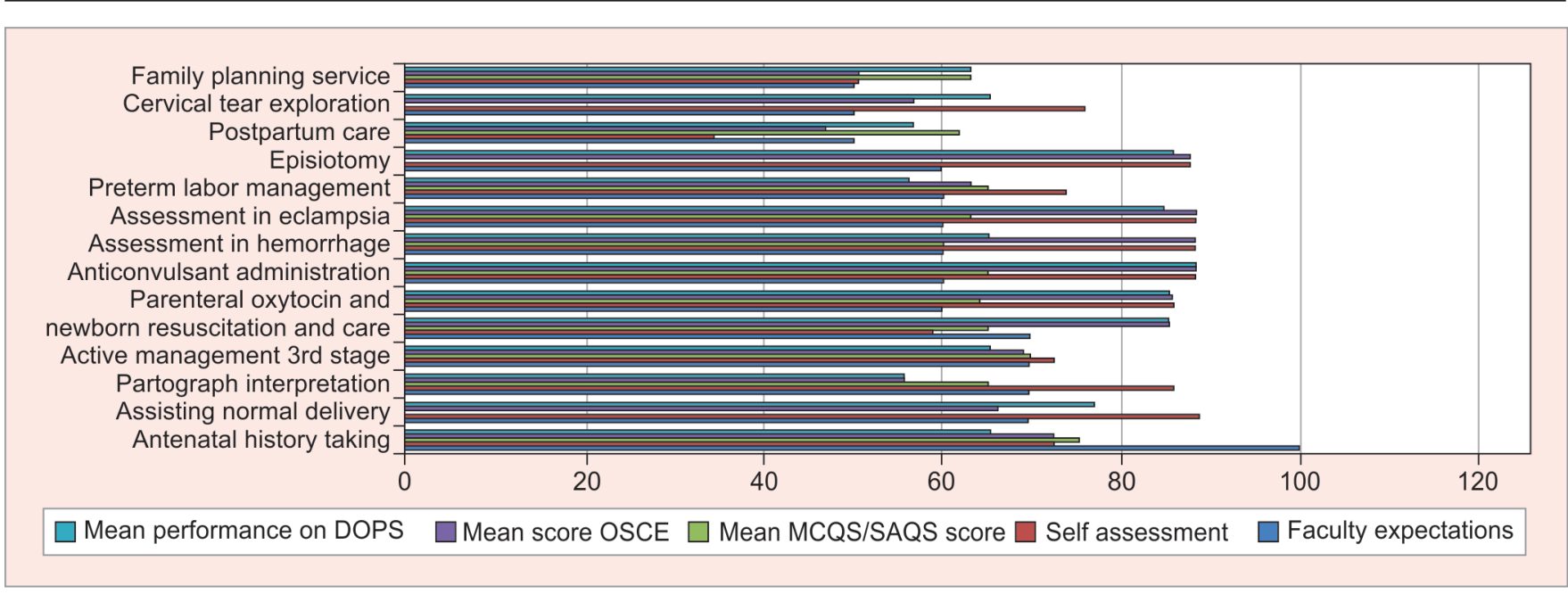

Graph 1: Faculty expectation, self assessment, mean MCQS/SAQS score, performance on OSCE and DOPS

$(50.3 \%)$, and neonatal resuscitation and care $(58.7 \%)$. The reason for lower confidence could be related to that little, or no hands-on training was provided in these competencies. Similar observations were made by Pierides et al. $^{2}$ who found that lesser confidence may be related to less exposure. These competencies may form thrust areas in subsequent training.

These competencies need to be given priority in planning the curriculum for subsequent maternity postings and internship training.

There is no doubt that midwifery services are crucial to the achievement of national and international goals in reproductive, maternal, newborn and child health, now and beyond.,

\section{CONCLUSION}

Undergraduate medical students are confident in assisting normal delivery and common clinical tasks in obstetrics.

Assessment of competencies has revealed that further training is needed in partogram interpretations, family planning, neonatal resuscitation and postpartum care in subsequent training.

\section{REFERENCES}

1. Norcini JJ, McKinley DW. Assessment methods in medical education. Teaching and Teacher Education 2007 Apr 1;23(3):239-250.

2. Pierides K, Duggan P, Chur-Hansen A, Gilson A. Medical student self-reported confidence in obstetrics and gynaecology: development of a core clinical competencies document. BMC Medical Education 2013 Dec;13(1):62-68.

3. Singh T, Modi JN. Workplace-based assessment: A step to promote competency based postgraduate training. Indian Pediatrics 2013 Jun 1;50(6):553-559.

4. Yigzaw T, Ayalew F, Kim YM, Gelagay M, Dejene D, Gibson H, et al. How well does pre-service education prepare midwives for practice: competence assessment of midwifery students at the point of graduation in Ethiopia. BMC Medical Education 2015 Dec;15(1):130-139.

5. Bettina UTZ, Siddiqui G, Adegoke A, Broek NVD. Definitions and roles of a skilled birth attendant: a mapping exercise from four South-Asian countries. ACTA Obstetricia et Gynecologica Scandinavica 2013;92:1063-1069 